\title{
COVID-19 in Socially Vulnerable Patients with Tuberculosis in Brazil
}

\author{
Eliza Miranda Ramos ${ }^{1,5}$, Emerson Luiz Lima Araújo ${ }^{2}$, James Venturini ${ }^{4}$, Gilberto Gonçalves Facco ${ }^{3}$, Cinthya \\ Cristina de Oliveira Canuto dos Reis ${ }^{5}$, Grazielle Franco Ferro da Costa Rodrigues ${ }^{5}$, Antônio Carlos de Abreu ${ }^{1}$, \\ Francisco José Mendes dos Reis ${ }^{1}$, Pamela Aline Miranda Teodoro ${ }^{1}$, Ernani Mendes da Fonseca Junior ${ }^{6}$, Rubens \\ César Ferreira Pereira ${ }^{7} \&$ Valter Aragão do Nascimento ${ }^{1}$
}

${ }^{1}$ Group of Spectroscopy and Bioinformatics Applied to Biodiversity and Health, School of Medicine, Postgraduation Program in Health and Development in the Midwest Region, Faculty of Medicine, Federal University of Mato Grosso do Sul, Campo Grande, Mato Grosso do Sul, Brazil

${ }^{2}$ Ministry of Health, Secretary of Health Surveillance, Department of Strategic Coordination of Health Surveillance, General Coordination of Public Health Laboratories, Brasília-DF, Brazil

${ }^{3}$ Graduate Program in Environments and Regional Development, Anhanguera University, UNIDERP, Mato Grosso do Sul, Brazil

${ }^{4}$ Federal University of Mato Grosso do Sul, Coordinator of the Postgraduate Program in Infectious and Parasitic Diseases (PPGDIP/UFMS), Campo Grande, Mato Grosso do Sul, Brazil

${ }^{5}$ Fundação para o Desenvolvimento Científico e Tecnológico em Saúde (FIOTEC/FIOCRUZ), Rio de Janeiro, Brazil

${ }^{6}$ Estácio de Sa University, Campo Grande, Mato Grosso do Sul, Brazil

${ }^{7}$ Federal University of Mato Grosso do Sul, Campo Grande, Mato Grosso do Sul, Brazil

Correspondence: Valter Aragão do Nascimento, Group of Spectroscopy and Bioinformatics Applied to Biodiversity and Health, School of Medicine, Postgraduation Program in Health and Development in the Midwest Region, Faculty of Medicine, Federal University of Mato Grosso do Sul, Campo Grande, Mato Grosso do Sul, Brazil. E-mail: aragao60@hotmail.com

Received: December 20, 2021 Accepted: January 23, 2022 Online Published: January 26, 2022

doi:10.5539/gjhs.v14n3p12 URL: https://doi.org/10.5539/gjhs.v14n3p12

\begin{abstract}
Introduction: COVID-19 is a global public health problem. The first case reported in the socially vulnerable population in the territory of Mato Grosso do State/Brazil occurred in August 2020. However, information about the co-infection of Tuberculosis (TB) and COVID-19 is rarely described in the world literature. Objective: to describe for the first time a group of vulnerable patients who died or not due to Tuberculosis and COVID-19, using a Cohort study of a control group and a treatment group.
\end{abstract}

Methods: Reporting 7 cases of TB associated with COVID-19 confirmed by respiratory RT-PCR, hospitalized in a hospital department of COVID-19 (CEAA: 42969320.0.0000.0021).

Results: The patients included in this case report were aged between 19 and 83 years, respectively, with a predominance of females, 4 patients were vaccinated with BCG. In addition, 3 patients died from COVID-19, and 2 patients were considered cured by COVID-19. The mean time to diagnosis between Tuberculosis and COVID-19 in the "control group" was 43 days and the mean time to diagnosis in the "treatment group" was 37 days. The average number of days of hospital stay in the "control group" was 50 days and in the "treatment group" it was 40 days. In the patients in the "control group", 2 presented a unilateral pulmonary cavity lesion on the X-ray. In the "treatment group", only 1 patient presented a unilateral pulmonary cavity lesion on the X-ray, and 2 presented a bilateral pulmonary cavity lesion, and only one developed bilateral non-cavitary lesion with infiltrates. Regarding drug resistance to the treatment of Tuberculosis, in the "treatment group" only 2 patients were sensitive and 3 were resistant. On the other hand, in the "control group", 1 patient presented resistance and 1 sensitivity. It was found that 4 patients with drug resistance to Tuberculosis died (57\%). Among the patients who died, it was observed that patients aged 83, 70 years and 66 years were not vaccinated with Bacillus Calmette-Guérin (BCG). It was found in this case report that patients with COVID-19 and Tuberculosis have $60 \%$ less chance of cure. Furthermore, patients cured with pulmonary sequelae of COVID-19 may be at greater risk of developing advances in the 
worsening of Tuberculosis in the future. However, according to the results found in this case report, in some socially vulnerable regions where the forms of advanced Tuberculosis occur there is the presence of drug-resistant Mycobacterium Tuberculosis strains.

Conclusion: Our study showed that Mycobactrium tuberculosis (MTB) infection in the socially vulnerable population increased the susceptibility to SARS-CoV-2 and the severity of COVID-19 or vice-versa. Based on this case report, it is recommended that, in the socially vulnerable population, the status of MTB infection be verified in patients with suspected COVID-19 at hospital admission.

Keywords: COVID-19, Tuberculosis, SARS-CoV-2, active, treatment

\section{Introduction}

The COVID-19 virus, designated as severe acute respiratory syndrome coronavirus 2 (SARS-CoV-2) in the period from 2000 to 2021 in vulnerable people in Brazil, has drawn the attention of public health researchers in Brazil regarding preventive, diagnostic and therapeutic actions (Zhou et al., 2020).

Recent scientific evidence suggests that individuals with tuberculosis are considered infectious as are individuals with SARS-CoV-2 (Zhou et al., 2020; Ramos et al., 2022). Thus, these diseases can spread quickly in the indigenous community due to the lack of inherited immunity, culminating in a high fatality rate among the elderly, as well as in patients with comorbidities such as Diabetes Mellitus. In fact, patients with COVID-19 present symptoms such as cough, fever, tiredness, dyspnea, and other signs that are similar to those of Tuberculosis (TB) and other respiratory infections caused by the virus (Fraisse, 2020; Ramos et al., 2020).

Tuberculosis and undergoing treatment occurred at the end of April 2020 in the vulnerable population of Mato Grosso do Sul State/Brazil. Therefore, after the notification of a patient with COVID-19 and Tuberculosis at the end of April 2020, the Brazilian socially vulnerable health department implemented a series of blocks across the socially vulnerable population in an attempt to interrupt the virus cycle, transmission and the redirection of resources, human and health infrastructure as an emergency response to the national effort to respond to the COVID-19 pandemic in Brazil (Ministério da Saúde, 2019; Ramos et al., 2022). Thus, these actions required the reconfiguration of current models of primary care in socially vulnerable health to support the new social distancing and preventive measures (WHO, 2020).

Thus, these actions caused changes that were reflected in the form of reductions in the frequency of clinical visits in order to minimize the risk of exposure to COVID-19 and changes in the methods used for direct observation therapy (DOT), since the traditional model of Tuberculosis treatment in these settings uses monthly dispensing of anti-TB drugs for self-administration at home (Ministério da Saúde, 2019; WHO, 2019). In Sierra Leone, the World Health Organization reported the impact of blockages in the provision of Tuberculosis care in the pandemic, mainly with the decrease in DOT (Ministério da Saúde, 2019; WHO, 2019). Therefore, in the year 2020 there were in Sierra Leone approximately 2.000 fewer notifications of Tuberculosis across the country, which corresponds to a reduction of $11.3 \%$ compared to 2019 due to the implementation of DOT (WHO, 2020; Vesga et al., 2020).

In the socially vulnerable population in Brazil, little is known about the relationship between COVID-19 and Tuberculosis (Glaziou, 2020). In this study, data from 7 cases (Cohort) that occurred in the Brazilian socially vulnerable territory were reported and demonstrated that patients with COVID-19 may develop complications of COVID-19 before, simultaneously or after the diagnosis of Tuberculosis.

Therefore, the aim of this study is to describe for the first time a group of socially vulnerable patients, who died from Tuberculosis and COVID-19 using a Cohort study of a control group and a treatment group.

\section{Methodology}

Data from the control and treatment cohorts were combined in order to assess mortality in the socially vulnerable population using the case report method. The Cohort study includes 7 patients with Tuberculosis and COVID-19, distributed in "control group" (With a negative result for COVID-19 and positive for Tuberculosis) and "treatment group" (With a positive result for COVID-19 and Tuberculosis). All patients residing in regions in Mato Grosso do Sul State with vulnerability and were admitted to hospitals located in the vicinity of these regions.

This research was approved by the Ethics Committee of the Federal University of Mato Grosso do Sul (UFMS), which is linked to the EPISUS project in the vulnerable villages population of Mato Grosso do Sul State, Brazil. The data analyzed refer to the period from 2020 to 2021. This study was approved by the Ethics Committee of ethic linked to the EPISUS project in the villages of Mato Grosso do Sul State, Brazil (CEAA: 42969320.0.0000.0021). The data analyzed refer to the period from 2020 to 2021. In all patients from the control group and treatment group included with a diagnosis of active tuberculosis and undergoing treatment and with 
COVID-19, the demographic and clinical variables were included, which were collected retrospectively, including comorbidities and risk factors for mortality.

The confirmation of patients with Tuberculosis and COVID-19 included in this study was performed using the RT-qPCR (molecular biology) technique. The first diagnosis of COVID-19 in patients with Tuberculosis in the vulnerable population in the territory occurred on August 20,2020, it is emphasized that this study was authorized by the UFMS ethics committee (CEAA: 42969320.0.0000.0021) and all data obtained ethical consent for use.

Continuous variables in this study, when not otherwise specified, were presented as medians. Categorical variables were described with absolute and relative frequency (percentage). A two-tailed $\mathrm{p}$ value less than 0.05 was considered statistically significant.

\section{Results}

Table 1 shows the demographic characteristics of patients confirmed in the period from 2021 to 2021 with presumptive Tuberculosis and confirmed by molecular biology during the intra-COVID-19 period. A total of 7 socially vulnerable patients tested positive for Tuberculosis, corresponding to 4 female patients $(57.1 \%)$ and 3 male patients $(42.9 \%)$. Overall, 5 patients belong to the "treatment group" Cohort and are distributed in the age group of 19 years (1), 29 years (1), 51 years (1), 66 years (1) and 83 years (1). On the other hand, two patients belong to the "control group" and are distributed in the age group of 51 years (1) and 70 years (1). In addition, 5 patients belonging to the "treatment group" tested positive for COVID-19.

Table 1. Demographic information of socially vulnerable of patients with Tuberculosis and COVID-19

\begin{tabular}{|c|c|c|c|c|c|c|}
\hline \multicolumn{7}{|c|}{ DEMOGRAPHIC DATA } \\
\hline Age & Male & Female & TUBECULOSIS & $\begin{array}{l}\text { COVID-19 } \\
\text { (RT-PCR } \\
\text { POSITIVE) }\end{array}$ & $\begin{array}{lr}\text { Patients } & \text { with } \\
\text { Covid-19 } & \text { Positive } \\
\text { Control Group or } \\
\text { treatment } \\
\text { POSITIVE) }\end{array}$ & $\begin{array}{lr}\text { Patients } & \text { without } \\
\text { COVID-19 (RT - PCR } \\
-\quad \text { Negative) Control } \\
\text { Group }\end{array}$ \\
\hline 19 & 0 & 1 & 1 & 1 & 1 & 0 \\
\hline 29 & 0 & 1 & 1 & 0 & 0 & 1 \\
\hline 51 & 1 & 1 & 2 & 1 & 1 & 1 \\
\hline 66 & 0 & 1 & 1 & 1 & 1 & 0 \\
\hline 70 & 1 & 0 & 1 & 0 & 1 & 0 \\
\hline 83 & 1 & 0 & 1 & 1 & 1 & 0 \\
\hline TOTAL & 3 & 4 & 7 & 4 & 5 & 2 \\
\hline
\end{tabular}

Source: UFMS-MS, 2021.

Table 2 shows the clinical evolutionary characteristics of socially vulnerable patients with a positive result for Tuberculosis. Only two patients had been diagnosed with COVID-19 before Tuberculosis (19 years and 51 years), in this case, the 19-year-old patient was diagnosed simultaneously with COVID-19 and Tuberculosis (4 days apart), on the other hand, 5 patients were diagnosed with COVID-19 after confirmation of Tuberculosis. Only two patients died unrelated to COVID-19, therefore, they had severe respiratory failure in the clinical course during the hospital stay. However, 3 patients died from COVID-19, 2 patients were considered cured for COVID-19 and the mean time of diagnosis between Tuberculosis and COVID-19 in the "control group" was 43 days and the mean time to diagnosis in the "treatment group" was 37 days.

The average number of days of hospital stay in the "control group" was 50 days and in the "treatment group" it was 40 days. In patients in the "control group", only 2 presented unilateral pulmonary cavity lesion on the X-ray. In the "treatment group", only 1 patient presented unilateral pulmonary cavity lesion on X-ray, however, 2 patients presented bilateral pulmonary cavity lesions and only one developed bilateral non-cavitary lesion with infiltrates. Regarding drug resistance to the treatment of Tuberculosis, in the "treatment group" only 2 patients were sensitive and 3 were resistant. In the "control group", 1 patient was resistant and 1 was sensitive to the drug. Table 2 shows that 4 patients with drug resistance to Tuberculosis died (57\%). 
Table 2. Clinical evolution of 7 of socially vulnerable of patients with Tuberculosis and COVID-19

\begin{tabular}{llllll}
\hline Age & $\begin{array}{l}\text { Time between } \\
\text { COVID-19 and TB } \\
\text { diagnosis (n } \mathbf{n}^{\mathbf{0}} \text { of } \\
\text { days) }\end{array}$ & $\begin{array}{l}\text { Clinical Evolution of } \\
\text { COVID-19 }\end{array}$ & $\begin{array}{l}\text { Time of } \\
\text { hospitalization } \\
\text { of days) }\end{array}$ & $\begin{array}{l}\text { Imaging during } \\
\text { TB/COVID-19 of course } \\
\text { Time }\end{array}$ & Drug Resistence \\
\hline 19 & 4 & Cured & 12 & Bilateral cavitary lesions & Sensitive \\
29 & 129 & Died Not of COVID-19 & 35 & Unilateral cavitary lesions & Resistence \\
51 & 10 & Cured & 32 & Unilateral cavitary lesions & Sensitive \\
51 & 36 & Died Not of COVID-19 & 65 & Unilateral cavitary lesions & Sensitive \\
66 & 130 & Died of COVID-19 & 56 & Bilateral cavitary lesions & Resistence \\
70 & 121 & Died of COVID-19 & 48 & Bilateral cavitary lesions & Resistence \\
83 & 89 & Died of COVID-19 & 51 & Bilateral infiltrates (no & Resistence \\
\hline
\end{tabular}

Source: UFMS-MS, 2021.

Table 3 shows the characteristics of 7 patients from the socially vulnerable population of co-infected with active/treated tuberculosis (TB) and Coronavirus in the period of 2021. Among the patients who died, only patients aged 83, 70 years and 66 years were not vaccinated with Bacillus Calmette-Guérin (BCG). However, 4 patients were infected with pan-susceptible strains and Mycobacterium Tuberculosis due to drug resistance, therefore, Mycobacterium bovis proved to be intrinsically resistant to topirazinamide (See Table 2).

The infection of 6 patients with SARS-CoV-2 was nosocomial (Table 3). Six patients required mechanical ventilation, but one patient did not use mechanical ventilation during the hospital stay (Table 3 ). In the "treatment group" of this case report, a median of 31 days after the diagnosis of COVID-19 was relevant to cause death or accelerate its occurrence. The overall fatality rate was $71 \%$ and the result seems consistent with those observed over time in other studies. Overall, 6 patients were affected by comorbidity, specifically Diabetes Mellitus (Table 3).

In all cases, COVID-19 favored to worsen the prognosis of patients with Tuberculosis and cause death (Table 2). The main limitation of this cohort study is that although it can report the majority of cases of Tuberculosis and COVID-19 in the vulnerable population, it cannot be considered representative for the entire Brazilian population.

Table 3. Characteristics of 7 patients co-infected with active/treated tuberculosis (TB) and Coronavírus in the socially vulnerable population disease, 2021

\begin{tabular}{|c|c|c|c|c|c|}
\hline Age & $\begin{array}{l}\text { Time between } \\
\text { COVID-19 and } \\
\text { TB diagnosis ( }{ }^{0} \\
\text { of days) }\end{array}$ & $\begin{array}{l}\text { Clinical presentation on } \\
\text { admission ( } n^{0} \text { of days) }\end{array}$ & $\begin{array}{l}\text { Status da TB } \\
\text { and Vaccine of } \\
\text { TB }\end{array}$ & $\begin{array}{l}\text { SpO2 \%, } \\
\text { respiratory rate } \\
\text { per minutes }\end{array}$ & $\begin{array}{l}\text { Mandatory critical care } \\
\text { and requires the use of } \\
\text { Mechanical Ventilation } \\
\text { and diabetics }\end{array}$ \\
\hline 13 & 4 & $\begin{array}{l}\text { Breathlessness for } 3 \text { days, fever } \\
\text { and } 4 \text { days. }\end{array}$ & Active/Yes & 92 & Not/Not \\
\hline 29 & 129 & $\begin{array}{l}\text { Breathlessness for } 7 \text { days, fever } \\
\text { for } 12 \text { days. }\end{array}$ & In treatment/Yes & 87 & Yes/Yes \\
\hline 51 & 10 & $\begin{array}{l}\text { Breathlessness for } 8 \text { days, fever } \\
\text { for } 9 \text { days. }\end{array}$ & Active/Yes & 90 & Yes/Yes \\
\hline 51 & 36 & $\begin{array}{l}\text { Breathlessness for } 4 \text { days, fever } \\
\text { for } 8 \text { days. }\end{array}$ & in treatment/Yes & 81 & Yes/Yes \\
\hline 66 & 130 & $\begin{array}{l}\text { Breathlessness for } 4 \text { days, fever } \\
\text { for } 6 \text { days, cough for } 2 \text { month. }\end{array}$ & in treatment/Not & 83 & Yes/Yes \\
\hline 70 & 121 & Fever for 15 days & in treatment/Not & 82 & Yes/Yes \\
\hline 83 & 89 & Fever for 14 days & in treatment/Not & 86 & Yes/Yes \\
\hline
\end{tabular}

Source: UFMS-MS, 2021. 


\section{Discussion}

Tuberculosis and COVID-19 have presented significant challenges in screening, treating and managing and controlling the infection (Tadoline et al., 2020). This study is the first case report in patients with Tuberculosis and COVID-19 in the vulnerable population. Thus, there is a great challenge for Brazilian public health to overcome the challenges inherent in the management of both diseases (Motta et al., 2020; Ramos et al., 2022). However, Brazil has taken new health policy decisions to meet the needs and help patients of socially vulnerable population in response to the pandemic (Andrade Junior et al., 2020).

Some of the deaths in this study of SARS-CoV-2 infection were nosocomial during the period from 2020 to 2021 , which were similar to that which occurred in Italy and Spain in the period of 2020 (Ramos et al., 2020). Thus, it is worth highlighting the importance of implementing strict infection control interventions for all hospitalized patients, particularly in patients at high risk of death due to age over 60 years and patients with comorbidities including Tuberculosis (Rodriguez-morales, 2020). The results of this study showed that the risk of viral transmission from other patients, visitors and health professionals to the socially vulnerable population in community must be taken into account, as limited or no protection against COVID-19 is one of the problems that leads to co-infection (Sy et al., 2020).

Another important factor is the age of patients, since it is the reason that can influence the increase in mortality in vulnerable of population in patients with COVID-19, when compared to other patients with other viral diseases that develop pneumonia or other injuries (Ramos et al., 2022; Vesga et al., 2020; Togun et al., 2020; STOP; Partnership, 2020).

Although the present study predicts mortality, due to the small number of patients using the Cohort study, we cannot draw specific conclusions. In fact, the findings of the study showed that in the "treatment group" there is mortality in elderly patients with comorbidity (Diabetes), with Tuberculosis being one of the main determinants of mortality in the vulnerable population people in Brazil (71\%) due to their age and greater number of comorbidities. Thus, this study demonstrated that the vulnerable population with Tuberculosis and COVID-19 have a higher risk of negative outcome and death compared to patients with COVID-19 alone. Therefore, early detection of the association between these diseases is important for the proper management of COVID-19 and Tuberculosis.

It is emphasized that patients with COVID-19 and Tuberculosis have $60 \%$ less chance of cure (Table 2). Furthermore, patients cured with pulmonary sequelae of COVID-19 may be at greater risk of developing advances in the worsening of Tuberculosis in the future.

However, according to the results found in this case report, it is observed that in vulnerable of population in some regions in Mato Grosso do Sul State where the forms of advanced Tuberculosis occur there is the presence of strains of Mycobacterium Tuberculosis that are resistant to drugs as shown in Table 2. Nevertheless, higher rates of deaths can be expected in young individuals as evidenced by previous studies (Amirlak et al., 2021).

The patients in this case report had respiratory problems and the clinical characteristics of patients with COVID-19 and those with active or under treatment Tuberculosis were fully elucidated. Due to the presence of respiratory problems in these patients, it is important to emphasize that the presence of cavitary disease on chest X-rays should be prioritized for the performance of the Multidrug-Resistant Tuberculosis (MDR-TB) and COVID-19 test (Miller et al., 2020; Athikarisamy, 2021).

Previous studies report that $20 \%$ of new MDR-TB cases occur in patients previously treated for Tuberculosis, and generally, patients who experience symptoms and disease recurrence should undergo laboratory tests for MDR-TB and COVID-19 (Sy et al., 2020; Eggenhuizen et al., 2021).

Given the above, it is important to implement strict infection control interventions for all hospitalized vulnerable population, which consider the risk of viral transmission from other patients, visitors and health professionals (Amirlak et al., 2021). In this case, greater care should be given to patients at high risk such as the elderly and patients with comorbidities including Tuberculosis (Gao et al., 2020; Andrade Junior et al., 2020).

The diagnosis of Tuberculosis during the period of the COVID-19 pandemic requires high clinical suspicion, as the two diseases have similar clinical signs, such as fever and mild or severe respiratory symptoms (Ramos et al., 2022). In addition, it is highlighted in this study that two patients were simultaneously diagnosed with COVID-19 and undiagnosed preexisting tuberculous disease (infection detected by chest X-ray) (Husain et al., 2020).

Therefore, COVID-19 may also have a negatively high impact on latent tuberculosis infection (Husain et al., 2020). Therefore, it is concluded in this study that immune dysregulation caused by COVID-19 affects the treatment and management of patients with latent tuberculosis infection (Table 3 and Table 4). The occurrence of mortality from 
Tuberculosis and COVID-19 linked to social distancing is largely to blame for the decrease in access to Tuberculosis healthcare and treatment (Pittet et al., 2021). This case report demonstrated that the absence of BCG vaccination is related to an increase in mortality in $60 \%$ of patients with a positive result for COVID-19 (Miller et al., 2020).

Therefore, due to the supporting evidence obtained in experimental studies and according to the results presented in Table 3, this case report emphasizes that the BCG vaccine generates a protective effect against viral pathogens such as COVID-19 (Pittet et al., 2021).

Given the above, this case report makes clear the importance of BGG vaccination as a booster to the immune system of the general population, especially for the vulnerable of population in patients (Pittet et al., 2021).

The impact caused by COVID-19 on the vulnerable of population is heterogeneous, as, in turn, it is attributed to the cultural difference in rules, mitigation efforts and especially health infrastructure (Amirlak et al., 2021).

According to Miller et al. (2020), the heterogeneity of the impact of COVID-19 can be explained in part by the different health policies linked to childhood BCG vaccination, which has been intensively reported for protection against respiratory infections. In addition, Miller et al. (2020), when associated with the number of BCG vaccination policies in some countries with morbidity and mortality from COVID-19, found that places without vaccination policies, such as Italy, the Netherlands and the USA, have a high rate of deaths by COVID-19 when compared to countries with universal vaccination policies such as Brazil for BCG (Amirlak et al., 2020; Eggenhuizen et al., 2021).

However, it should be noted that vaccination for BCG does not generate unique and specific protection for COVID-19, but it strengthens the immune system and can lead to a higher percentage of protection and simultaneously a milder infection by the virus, in this case, COVID- 19.

COVID-19 causes a known and exaggerated immune response, which leads to the disordered production of cytokines and pro-inflammatory proteins, in this case, the "Cytokine Storm" (Eggenhuizen et al., 2021). On the other hand, the BCG vaccine helps to organize the inflammatory response more efficiently, avoiding an uncontrolled immunological activity in order to reduce morbidity and mortality, therefore, using the BCG vaccine can be a possible tool in the fight against COVID-19 (Husain et al., 2020; Mehta et al., 2020; Athikarisamy, 2021).

\section{Conclusion}

Taking into account the results found in this case report, it seems that Tuberculosis like COVID-19 are two diseases that pose great challenges to public health in Brazil, especially when it involves the vulnerable population.

Given the above, it is noted that it is necessary to create policies to combat the pandemic in the Brazilian vulnerable population, but it is necessary to systematically carry out the fight against Tuberculosis. Given the above, it is noted that it is necessary to create policies to combat the pandemic in the Brazilian vulnerable population, but it is necessary to systematically carry out the fight against Tuberculosis. The study highlights the importance of considering the screening and management of these two infections that are causes of mortality mainly in the vulnerable population, justifying a common public health implication.

Infection with Mycobactrium tuberculosis (MTB) in the vulnerable population increased the susceptibility to SARS-CoV-2 and the severity of COVID-19. Thus, based on this case report study, it is recommended that in the indigenous population, the status of MTB infection is verified in patients with suspected COVID-19 at hospital admission.

\section{Competing Interests Statement}

The authors declare that there are no competing or potential conflicts of interest.

\section{References}

Amirlak, L., Haddad, R., Hardy, J. D., Khaled, N. S., Chung, M. H., \& Amirlak, B. (2021). Effectiveness of booster BCG vaccination in preventing Covid-19 infection. Human Vaccines \& Immunotherapeutics, 1-3. PMID: 34403297; PMCID: PMC8425429. https://doi.org/10.1080/21645515.2021.1956228

Andrade Júnior, F. P. de, Silva Neta, M. das N., Silva, K. S. da, Moraes, G. F. Q., Teixeira, A. P. de C., Lima, I. O., \& Lima, E. de O. (2020). Antituberculosis in pregnancy: a review. Research, Society and Development, 9(6), 2020, e118963714. https://doi.org/10.33448/rsd-v9i6.3714

Athikarisamy, S. E., \& Jacob, J. R. (2021). Does BCG bolster one's immunity against COVID-19? Rapid response in theBMJ 2020. Retrieved August 19, 2021, from, https://www.bmj.com/content/368/bmj.m1252/rr 
Chen, Y., Wang, Y., Fleming, J., Yu, Y., Gu, Y., Liu, C., ... \& Liu, Y. (2020). Active or latent tuberculosis increases susceptibility to COVID-19 and disease severity. MedRxiv. https://doi.org/10.1101/2020.03.10.20033795

Cilloni, L., Fu, H., Vesga, J. F., Dowdy, D., Pretorius, C., Ahmedov, S., ... \& Arinaminpathy, N. (2020). The potential impact of the COVID-19 pandemic on the tuberculosis epidemic a modelling analysis. EClinicalMedicine, 28, 100603.20 Retrieved from https://stoptb.org/assets/documents/news/Modeling\%20Report_1\%20May\%202020_FINAL.pdf

Diao, B., Wang, C., Tan, Y., Chen, X., Liu, Y., Ning, L., ... \& Chen, Y. (2020). Reduction and functional exhaustion of $\mathrm{T}$ cells in patients with coronavirus disease 2019 (COVID-19). Frontiers in immunology, 11, 827. https://doi.org/10.3389/fimmu.2020.00827

Eggenhuizen, P. J., Ng, B. H., Chang, J., Fell, A. L., Cheong, R. M., Wong, W. Y., ... \& Ooi, J. D. (2021). BCG vaccine derived peptides induce SARS-CoV-2 T cell cross-reactivity. Frontiers in Immunology, 3034. PMID: 34421902; PMCID: PMC8374943. https://doi.org/10.3389/fimmu.2021.692729

Fraisse, P. (2020). Impact de l'épidémie de Covid-19 sur l'activité des centres de lutte antituberculeuse. Réseau national des centres de lutte antituberculeuse. GREPI. Retrieved from http://splf.fr/covid-19-informations-aux-professionnels

Gao, Y., Liu, M., Chen, Y., Shi, S., Geng, J., \& Tian, J. (2020). Association between tuberculosis and COVID-19 severity and mortality: A rapid systematic review and meta-analysis. Journal of medical virology. https://doi.org/10.1002/jmv.26311

Glaziou, P. (2020). Predicted impact of the COVID-19 pandemic on global tuberculosis deaths in 2020. MedRxiv. https://doi.org/10.1101/2020.04.28.20079582

Husain, A. A., Monaghan, T. M., \& Kashyap, R. S. (2021). Impact of COVID-19 pandemic on tuberculosis care in India. Clinical Microbiology and Infection, 27(2), 293. https://doi.org/10.1016/j.cmi.2020.08.014

Mehta, P., McAuley, D. F., Brown, M., Sanchez, E., Tattersall, R. S., \& Manson, J. J. (2020). COVID-19: consider cytokine storm syndromes and immunosuppression. The lancet, 395(10229), 1033-1034. https://doi.org/10.1016/S0140-6736(20)30628-0

Miller, A., Reandelar, M. J., Fasciglione, K., Roumenova, V., Li, Y., \& Otazu, G. H. (2020). Correlation between universal BCG vaccination policy and reduced mortality for COVID-19. MedRxiv. https://doi.org/10.1101/2020.03.24.20042937

Ministério da Saúde. (2019). MANUAL DE RECOMENDAÇÕES PARA O CONTROLE DA TUBERCULOSE NO BRASIL. $\quad 2^{\mathrm{a}}$ edição atualizada. https://bvsms.saude.gov.br/bvs/publicacoes/manual_recomendacoes_controle_tuberculose_brasil_2_ed.pdf

Motta, I., Centis, R., D’Ambrosio, L., García-García, J. M., Goletti, D., Gualano, G., ... \& Migliori, G. B. (2020). Tuberculosis, COVID-19 and migrants: preliminary analysis of deaths occurring in 69 patients from two cohorts. Pulmonology, 26(4), 233-240. https://doi.org/10.1016/j.pulmoe.2020.05.002

Pittet, L. F., Messina, N. L., Gardiner, K., Orsini, F., Abruzzo, V., Bannister, S., ... \& Curtis, N. (2021). BCG vaccination to reduce the impact of COVID-19 in healthcare workers: Protocol for a randomised controlled trial (BRACE trial). BMJ open, 11(10), e052101. PMID: 34711598; PMCID: PMC8557250. https://doi.org/10.1136/bmjopen-2021-052101

Ramos, E. M., Araújo, E. L. L., dos Reis, F. J. M., de Souza, I. D., Facco, G. G., Ramos, I. B., ... \& do Nascimento, V. A. (2022). Vitamin D, Zinc and Iron in Adult Patients with Covid-19 and Their Action in the Immune Response as Biomarkers. Global Journal of Health Science, 14(1), 1-1. https://doi.org/10.5539/gjhs.v14n1p1

Ramos, E. M., de Abreu, A. C., de Freitas, S. L. F., de Lima, M. D., dos Reis, F. J. M., Ramos, H. V., ... \& do Nascimento, V. A. (2020). COVID-19, rate of case factors and nutritional characteristics of patients dying in Italy and Brazil: a critical analyze. Global J Health Sci, 12(7), 133. https://doi.org/10.5539/gjhs.v12n7p133

Ravimohan, S., Kornfeld, H., Weissman, D., \& Bisson, G. P. (2018). Tuberculosis and lung damage: from epidemiology to pathophysiology. European Respiratory Review, 27(147). https://doi.org/10.1183/16000617.0077-2017

Rodriguez-Morales, A. J., Cardona-Ospina, J. A., Gutiérrez-Ocampo, E., Villamizar-Peña, R., Holguin-Rivera, Y., Escalera-Antezana, J. P., ... \& Sah, R. (2020). Clinical, laboratory and imaging features of COVID-19: A systematic review and meta-analysis. Travel medicine and infectious disease, 34, 101623. PMCID: PMC7102608. https://doi.org/10.1016/j.tmaid.2020.101623 
Sy, K. T. L., Haw, N. J. L., \& Uy, J. (2020). Previous and active tuberculosis increases risk of death and prolongs recovery in patients with COVID-19. Infectious Diseases, 52(12), 902-907. https://doi.org/10.1080/23744235.2020.1806353

Tadolini, M., Codecasa, L. R., García-García, J. M., Blanc, F. X., Borisov, S., Alffenaar, J. W., ... \& Migliori, G. B. (2020). Active tuberculosis, sequelae and COVID-19 co-infection: first cohort of 49 cases. European Respiratory Journal, 56(1). https://doi.org/10.1183/13993003.01398-2020

Togun, T., Kampmann, B., Stoker, N. G., \& Lipman, M. (2020). Anticipating the impact of the COVID-19 pandemic on TB patients and TB control programmes. Annals of clinical microbiology and antimicrobials, 19, 1-6. https://doi.org/10.1186/s12941-020-00363-1

Vesga, J. F., Hallett, T. B., Reid, M. J., Sachdeva, K. S., Rao, R., Khaparde, S., ... \& Arinaminpathy, N. (2019). Assessing tuberculosis control priorities in high-burden settings: a modelling approach. The Lancet Global Health, 7(5), e585-e595. https://doi.org/10.1016/S2214-109X(19)30037-3

World Health Organization [WHO]. (2020). COVID-19 Coronavirus Pandemic; 2020 Retrieved from https://www.who.int/emergencies/diseases/novelcoronavirus2019? adgroupsurvey $=\{$ adgroupsurvey $\}$ \&gclid $=$ CjwKCAiA55mPBhBOEiwANmzoQiRypEpVYPfcS2gVAFB566MUo7UeyvzEXOrpz1FsiYw_1Ek_BHe yRoC8TMQAvD_BwE

World Health Organization [WHO]. (2020). Global Tuberculosis Report; 2019 Retrieved from file://C:/Users/adminsgi/Downloads/9789241565714-eng.pdf

Zhou, P., Yang, X. L., Wang, X. G., Hu, B., Zhang, L., Zhang, W., ... \& Shi, Z. L. (2020). A pneumonia outbreak associated with a new coronavirus of probable bat origin. nature, 579(7798), 270-273. PMCID: PMC7095418. https://doi.org/10.1038/s41586-020-2012-7

\section{Copyrights}

Copyright for this article is retained by the author(s), with first publication rights granted to the journal.

This is an open-access article distributed under the terms and conditions of the Creative Commons Attribution license (http://creativecommons.org/licenses/by/4.0/). 